\title{
Design a New Fuzzy Optimize Robust Sliding Surface Gain in Nonlinear Controller
}

\author{
Mohammad Shamsodini \\ Department of Electrical, Bushehr Branch (Delvar Center), Islamic Azad University, Bushehr, Iran \\ E-mail: shayan.shamsaddini@yahoo.com \\ Rouholla Manei \\ Department of Electrical, Bushehr Branch (Delvar Center), Islamic Azad University, Bushehr, Iran \\ E-mail: manei_r@yahoo.com
}

\author{
Ali Bekter \\ Department of Electrical, Bushehr Branch (Delvar Center), Islamic Azad University, Bushehr, Iran \\ E-mail:a_bekter@yahoo.com \\ Babak Ranjbar \\ Department of Electrical, Bushehr Branch (Delvar Center), Islamic Azad University, Bushehr, Iran \\ E-mail: shayan.shamsaddini@yahoo.com
}

Samira Soltani

Research and Development Department, Artificial Control and Robotics Lab., Institute of Advance Science and Technology-SSP, Shiraz, Iran

E-mail: SSP.ROBOTIC@yahoo.com,WWW.IRANSSP.COM

\begin{abstract}
Control of robotic manipulator is very important in field of robotic, because robotic manipulators are multi-input multi-output (MIMO), nonlinear and most of dynamic parameters are uncertainty. Today, robot manipulators used in unknown and unstructured environment which caused to provides sophisticated systems, therefore strong mathematical tools used in new control methodologies to design adaptive nonlinear robust controller with acceptable performance (e.g., minimum error, good trajectory, disturbance rejection). One of the best nonlinear robust controller which can be used in uncertainty nonlinear systems, are sliding mode controller but pure sliding mode controller has some disadvantages therefore this research focuses on the design fuzzy sliding mode controller. One of the most important challenging in pure sliding mode controller and sliding mode fuzzy controller is sliding surface slope. This paper focuses on adjusting the sliding surface slope in sliding mode fuzzy controller to have the best performance and reduce the limitation.
\end{abstract}

Index Terms - Classical Control, Non-Classical Control, Fuzzy Logic, Sliding Mode Controller, Sliding Surface Slope, Sliding Mode Fuzzy Controller

\section{Introduction, Background and Motivation}

A robot system without any controllers does not to have any benefits, because controller is the main part in this sophisticated system. The main objectives to control of robot manipulators are stability, and robustness. Lots of researchers work on design the controller for robotic manipulators to have the best performance. Control of any systems divided in two main groups: linear and nonlinear controller [1]. However, one of the important challenging in control algorithms is design linear behavior controller to easier implementation for nonlinear systems but these algorithms have some limitation such as controller working area must to be near the system operating point and this adjustment is very difficult specially when the dynamic system parameters have large variations, and when the system has hard nonlinearities [1]. Most of robot manipulators which work in industry are usually controlled by linear PID controllers. But the robot manipulator dynamic functions are, nonlinear with strong coupling between joints (low gear ratio), structure and unstructured uncertainty, and multi- inputs mu lti-outputs (MIMO) which, design linear controller is very difficult especially if the velocity and acceleration of robot manipulator be high and also when the ratio between joints gear be small [2]. To eliminate above problems in physical systems most of control researcher go toward to select nonlinear robust controller. One of 
the most important powerful nonlinear robust controllers is sliding mode controller (SMC). However Sliding mode control methodology was first proposed in the 1950 but this controller has been analyzed by many researchers in recent years. The main reason to select this controller in wide range area is have an acceptable control performance and solve some main challenging topics in control such as resistivity to the external disturbance and uncertainty. However, this controller has above advantages but, pure sliding mode controller has following disadvantages i.e. chattering problem, sensitive, and equivalent dynamic formu lation [3]. After the invention of fuzzy logic theory in 1965 by Zadeh (Zadeh, 1997), this theory was used in wide range area because Fuzzy logic controller (FLC) is one of the most important applications of fuzzy logic theory. This controller can be used to control of nonlinear, uncertain, and noisy systems. However pure FLC works in many engineering applications but, it cannot guarantee two most important challenges in control, namely, stability and acceptable performance [4-18]. So me researchers applied fuzzy logic methodology in sliding mode controllers (FSMC) to reduce the chattering and solve the nonlinear dynamic equivalent problems in pure sliding mode controller and the other researchers applied sliding mode methodology in fuzzy logic controller (SMFC) to improve the stability of systems, therefore FSMC is a controller based on SMC but SMFC works based on FLC. Adaptive control used in systems whose dynamic parameters are varying and/or have unstructured disturbance and need to be training on line. Adaptive fuzzy inference system provide a good knowledge tools for adjust a complex uncertain nonlinear system with changing dynamics to have an acceptable performance. Combined adaptive method to artificial sliding mode controllers can help to controllers to have a better performance by online tuning the nonlinear and time variant parameters [5-22]. This paper is organized as follows:

In section 2, dynamic formulation of robot manipulator is presented, detail of classical SMC. In section 3, design sliding mode fuzzy controller and design adaptive sliding mode fuzzy controller are presented; this method is used to reduce the chattering and estimation the equivalent part. In section 4 , the simulation result is presented and finally in section 5, the conclusion is presented.

\section{Robot Manipulator Dynamics, Objectives, Problem Statements and Feedback Linearization Formulation}

Robot manipulator dynamic formulation: The equation of an $n-D O F$ robot manipulator governed by the following equation [1, 3, 15-29]:

$$
M(q) \ddot{q}+N(q, \dot{q})=\tau
$$

Where $\tau$ is actuation torque, $\mathrm{M}(\mathrm{q})$ is a symmetric and positive define inertia matrix, $N(q, \dot{q})$ is the vector of nonlinearity term. This robot manipulator dynamic equation can also be written in a following form:

$$
\tau=M(q) \ddot{q}+B(q)[\dot{q} \dot{q}]+C(q)[\dot{q}]^{2}+G(q)
$$

Where $\mathrm{B}(\mathrm{q})$ is the matrix of coriolios torques, $\mathrm{C}(\mathrm{q})$ is the matrix of centrifugal torques, and $\mathrm{G}(\mathrm{q})$ is the vector of gravity force. The dynamic terms in equation (2) are only manipulator position. This is a decoupled system with simple second order linear differential dynamics. In other words, the component $\ddot{q}$ influences, with a double integrator relationship, only the joint variable $q_{i}$, independently of the motion of the other joints. Therefore, the angular acceleration is found as to be [3, 10-22]:

$$
\ddot{q}=M^{-1}(q) .\{\tau-N(q, \dot{q})\}
$$

Sliding Mode Controller: Sliding mode controller (SMC) is a powerful nonlinear controller which has been analyzed by many researchers especially in recent years. This theory was first proposed in the early 1950 by Emelyanov and several co-workers and has been extensively developed since then with the invention of high speed control devices [1-18].

A time-varying sliding surface $\boldsymbol{s}(\boldsymbol{x}, \boldsymbol{t})$ is given by the following equation:

$$
s(x, t)=\left(\frac{d}{d t}+\lambda\right)^{n-1} \tilde{x}=0
$$

The derivation of $S$, namely, $\dot{S}$ can be calculated as the following formulation:

$$
\dot{S}=\left(\ddot{\mathbf{x}}-\ddot{\mathbf{x}}_{\mathbf{d}}\right)+\lambda\left(\dot{\mathbf{x}}-\dot{\mathbf{x}}_{\mathbf{d}}\right)
$$

suppose define the second order system as,

$$
\ddot{x}=f+u \rightarrow \dot{S}=f+U-\ddot{x}_{d}+\lambda\left(\dot{\mathbf{x}}-\dot{\mathbf{x}}_{\mathrm{d}}\right)
$$

Where $f$ is the dynamic uncertain, and also if $S=0$ and $\dot{S}=0$, to have the best approximation , $\widehat{U}$ defined by,

$$
\widehat{U}=-\widehat{f}+\ddot{x}_{d}-\lambda\left(\dot{\mathbf{x}}-\dot{\mathbf{x}}_{\mathbf{d}}\right)
$$

A simple solution to get the sliding condition when the dynamic parameters have uncertainty is the switching control law:

$$
U_{d i s}=\widehat{U}-K(\vec{x}, t) . \operatorname{sgn}(s)
$$

Where the function of $\boldsymbol{s} \boldsymbol{g n}(\boldsymbol{S})$ defined as; 


$$
\operatorname{sgn}(s)= \begin{cases}1 & s>0 \\ -1 & s<0 \\ 0 & s=0\end{cases}
$$

To reduce or eliminate the chattering it is used the boundary layer method; in boundary layer method the basic idea is replace the discontinuous method by saturation (linear) method with small neighborhood of the switching surface. This replace is caused to increase the error performance.

$$
\boldsymbol{B}(\boldsymbol{t})=\{\boldsymbol{x},|\boldsymbol{S}(\boldsymbol{t})| \leq \emptyset\} ; \emptyset>0
$$

Where $\emptyset$ is the boundary layer thickness. Therefore, to have a smote control law, the saturation function $\boldsymbol{S a t}(\boldsymbol{S} / \varnothing)$ added to the control law:

$$
U=K(\vec{x}, t) . S a t(S / \varnothing)
$$

Where $\boldsymbol{S a t}(\boldsymbol{S} / \varnothing)$ can be defined as

$$
\operatorname{sat}(s / \varnothing)=\left\{\begin{array}{cr}
1 & (s / \varnothing>1) \\
-1 & (s / \varnothing<1) \\
s / \varnothing & (-1<s / \varnothing<1)
\end{array}\right.
$$

Based on above discussion, the control law for a multi degrees of freedom robot manipulator is written as:

$$
\hat{\boldsymbol{\tau}}=\hat{\boldsymbol{\tau}}_{e q}+\hat{\boldsymbol{\tau}}_{\text {sat }}
$$

Where, the model-based component $\hat{\boldsymbol{\tau}}_{\boldsymbol{e q}}$ is compensated the nominal dynamics of systems. Therefore $\hat{\boldsymbol{\tau}}_{\boldsymbol{e q}}$ can calculate as follows:

$$
\widehat{\boldsymbol{\tau}}_{e q}=\left[\boldsymbol{M}^{-1}(B+C+G)+\dot{S}\right] M
$$

Suppose that $\boldsymbol{\tau}_{\text {sat }}$ is computed as

$$
\hat{\boldsymbol{\tau}}_{\text {sat }}=\operatorname{K} \cdot \operatorname{sat}(S / \emptyset)
$$

Moreover by replace the formulation (14) and (15) in (13) the control output is written as ;

$$
\begin{aligned}
& \hat{\boldsymbol{\tau}}=\left[M^{-1}(B+C+G)+\dot{S}\right] M+ \\
& \text { K. sat }(S / \varnothing)
\end{aligned}
$$

Figure 1 shows the position classical sliding mode control for robot manipulator.

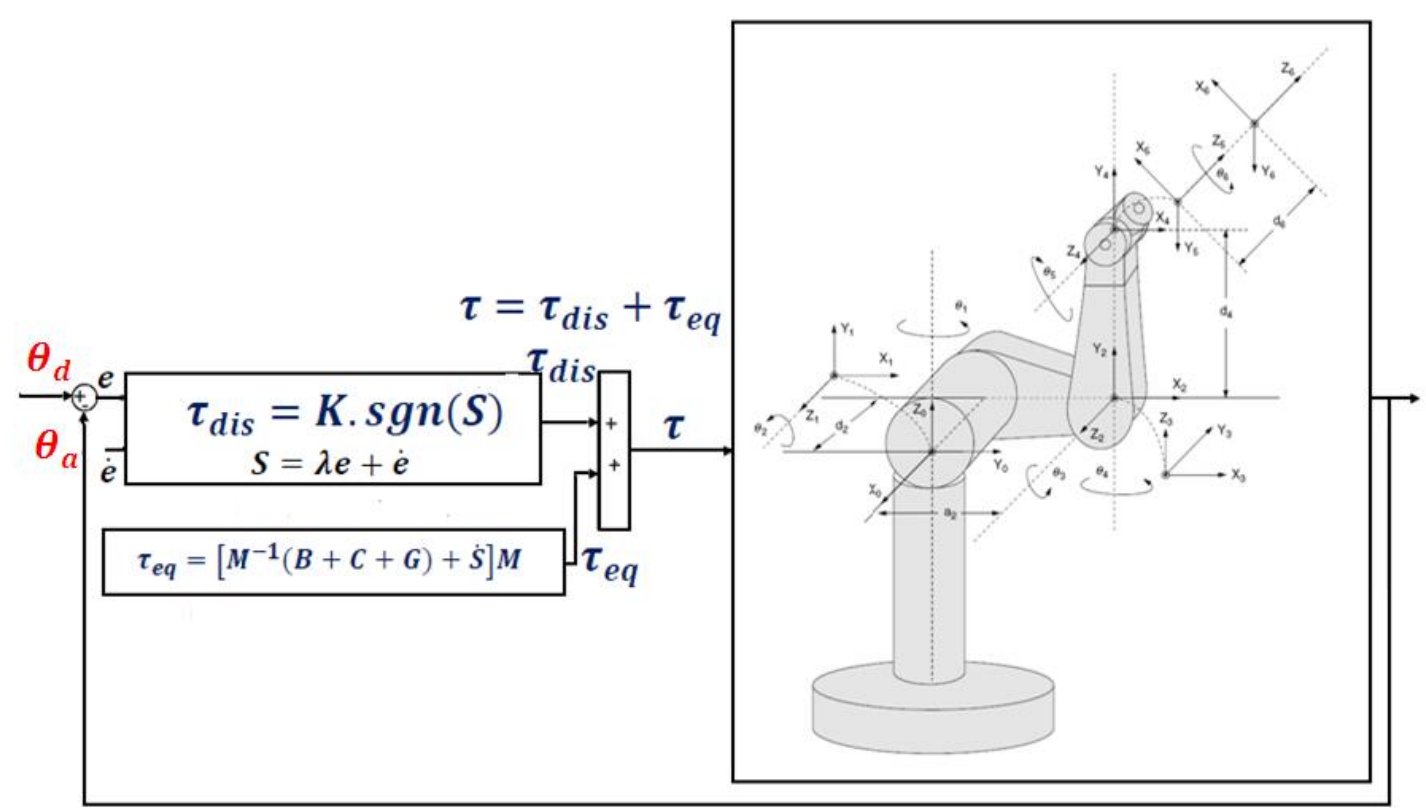

Fig. 1: Block diagram of classical sliding mode controller

Sliding Mode Fuzzy Controller: As shown in Figure 1, sliding mode controller divided into two main parts: equivalent controller, based on dynamics formu lation of robot manipulators and sliding surface saturation part based on saturation continuous function to reduce the chattering. Boundary layer method (saturation function) is used to reduce the chattering. Reduce or eliminate the chattering regarding to reduce the error is play important role in this research therefore boundary layer method is used beside the equivalent part to solve the chattering problem besides reduce the error.

Combinations of fuzzy logic systems with sliding mode method have been proposed by several researchers. SMFC is fuzzy controller based on sliding 
mode method for easy implementation, stability, and robustness. Control rules for SMFC can be described as:

\section{IF $\mathrm{S}$ is $<$ ling.var $>$ THEN $\mathrm{U}$ is $<$ ling.var $>$}

Table 1 is shown the fuzzy rule table for SMFC, respectively:
Table1: Rule table (SMFC)

\begin{tabular}{|c|c|c|c|c|c|c|c|}
\hline S & NB & NM & NS & Z & PS & PM & PB \\
\hline T & NB & NM & NS & Z & PS & PM & PB \\
\hline
\end{tabular}

A block diagram for sliding mode fuzzy controller shows in Figure 2.

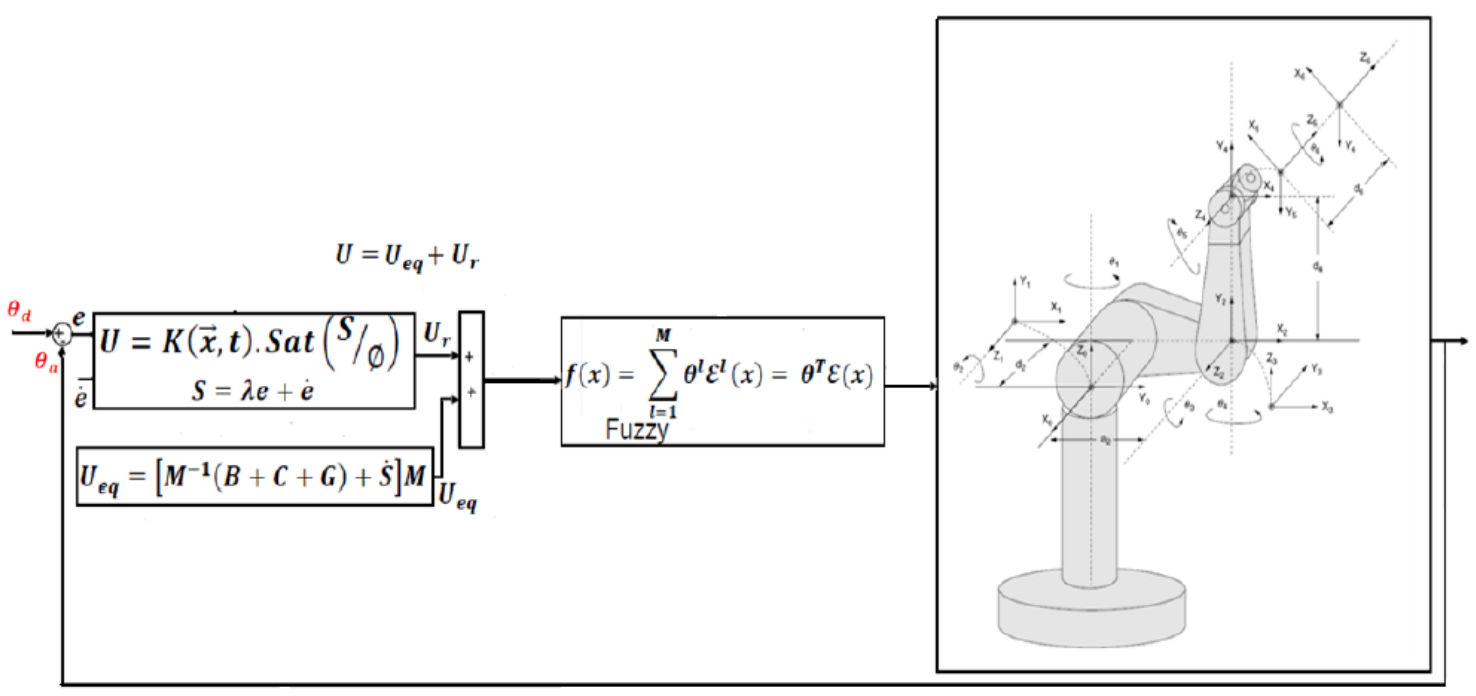

Fig. 2: $\quad$ Sliding Mode Fuzzy Control of robot manipulator (SMFC)

It is basic that the system performance is sensitive to the sliding surface slope $\lambda$ for sliding mode fuzzy controller. For instance, if large value of $\lambda$ are chosen the response is very fast but the system is very unstable and conversely, if small value of $\lambda$ considered the response of system is very slow but the system is very stable. Therefore, calculate the optimum value of $\lambda$ for a system is one of the most important challenging works. SMFC has two most important advantages i.e. the number of rule base is smaller and Increase the robustness and stability.

In this method the control output can be calculated by

$$
\tau=\hat{\imath}+\tau_{f u z z y(S)}
$$

Where $\widehat{\boldsymbol{\tau}}$ the nominal compensation is term and $\boldsymbol{\tau}_{f u z z y(s)}$ is the output of sliding mode fuzzy controller [9].

\section{Methodology: Sliding Surface Gain Adjustment}

For nonlinear, uncertain, and time-variant plants (e.g., robot manipulators) adaptive method can be used to self adjusting the surface slope and gain updating factors. Research on adaptive sliding mode fuzzy controller is significantly growing, for instance, the different ASMFC have been reported in [5]; [10-12]. It is a basic fact that the system performance in SMFC is sensitive to sliding surface slope, $\lambda$. Thus, determination of an optimum $\lambda$ value for a system is an important problem. If the system parameters are unknown or uncertain, the problem becomes more highlighted. This problem may be solved by adjusting the surface slope and boundary layer thickness of the sliding mode controller continuously in real-time. To keep the structure of the controller as simple as possible and to avoid heavy computation, a new supervisor tuner based on updated by a new coefficient factor $k n$ is presented. In this method the supervisor part tunes the output scaling factors using gain online updating factors. The inputs of the supervis or term are error and change of error $(e, \dot{e})$ and the output of this controller is $U$, which it can be used to tune sliding surface slope, $\lambda$.

$$
\begin{gathered}
\boldsymbol{k}_{\boldsymbol{n}}=\boldsymbol{e}^{\mathbf{2}}-\frac{\left(\boldsymbol{r}_{\boldsymbol{v}}-\boldsymbol{r}_{\boldsymbol{v} \text { min }}\right)^{\mathbf{5}}}{\mathbf{1}+|\boldsymbol{e}|}+\boldsymbol{r}_{\boldsymbol{v} \text { min }} \\
r_{v}=\frac{(d e(k)-d e(k-1))}{d e(.)} \\
\operatorname{de}(.)=\left\{\begin{array}{ll}
\operatorname{de}(k) ; & \text { if } \operatorname{de}(k) \geq \operatorname{de}(k-1) \\
\operatorname{de}(k-1) & \text { if } \operatorname{de}(k)<\operatorname{de}(k-1)
\end{array}\right\}
\end{gathered}
$$

In this way, the performance of the system is improved with respect to the SMFC controller. 


\section{Simulation Results}

Classical sliding mode control (SMC), sliding mode fuzzy control (SMFC), and adaptive sliding mode fu zzy control (ASMFC) are implemented in Matlab/Simulink environment. In theses controllers changing updating factor performance, tracking performance, error, and robustness are compared.

Changing Sliding Surface Slope performance: For various value of sliding surface slope $(\lambda)$ in SMC, and ASMFC the trajectory performances have shown in Figures 3 and 4.
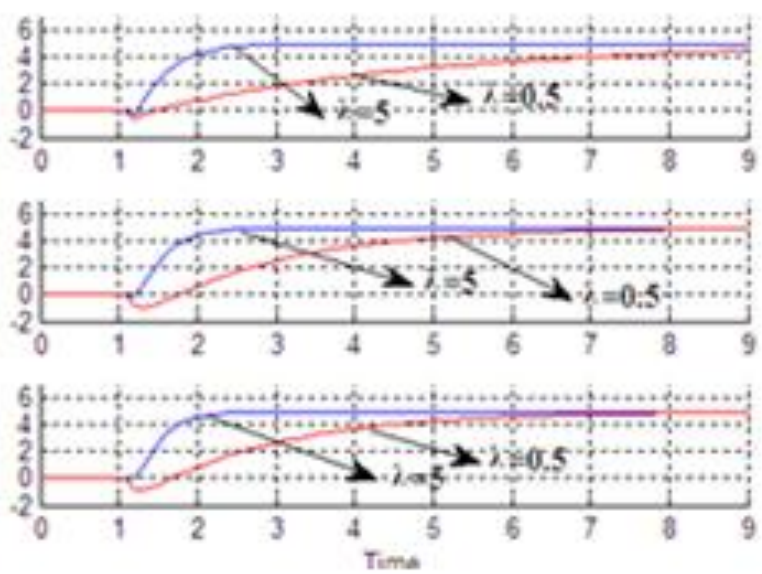

Fig. 3: SMC trajectory in first, second and third link
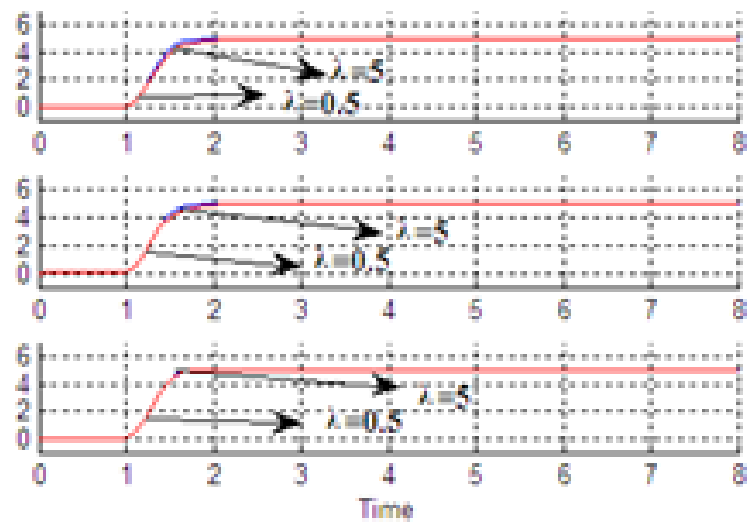

Fig. 4: ASMFC trajectory performance in first, second and third links

Figures 3 and 4 are shown trajectory performance with different sliding surface slope; it is seen that AFSMC has the better performance in comparison with classical SMC.

Tracking performances: Figures 5, 6 and 7 are shown tracking performance for first, second and third link in SMC, SMFC and AFSMC without disturbance for step trajectories. By comparing step response trajectory without disturbance in SMC, SMFC and AFSMC it is found that the SMC's overshoot $(1.32 \%)$ is lower than SMFC's and ASMFC's (2.44\%), although all of them have about the same rise time; AFSMC $(0.5 \mathrm{sec})$ and SMC, and SMFC $(0.403 \mathrm{sec})$. Besides the Steady State and RMS error in SMC and ASMFC (Steady State error $=0$ and RMS error $=0$ ) is fairly lower than SMFC (Steady State error $\cong-\mathbf{3}^{-\mathbf{5}}$ and $\mathrm{RMS}$ error $=\mathbf{- 1 . 6} \times$ $10^{-5}$ ).

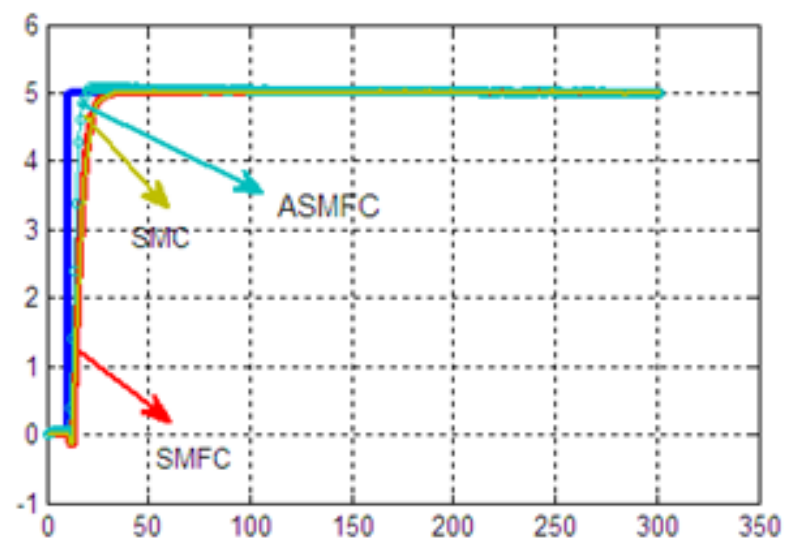

Fig. 5: First link trajectory without disturbance

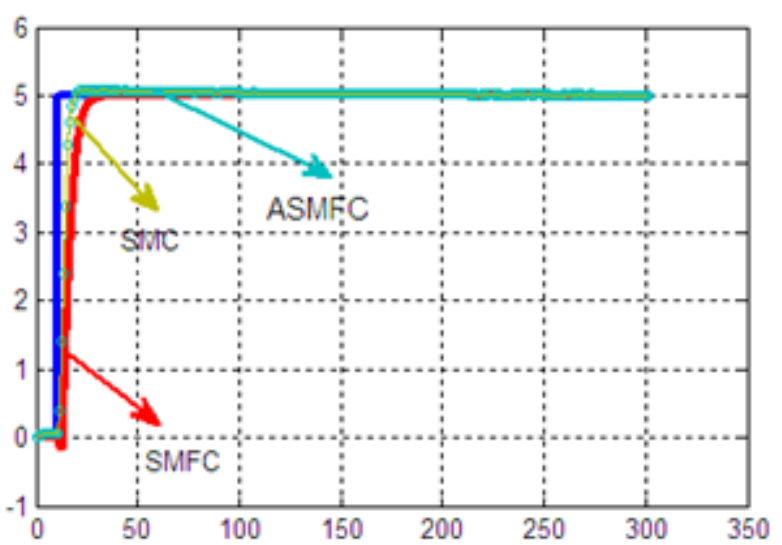

Fig. 6: Second link trajectory without disturbance

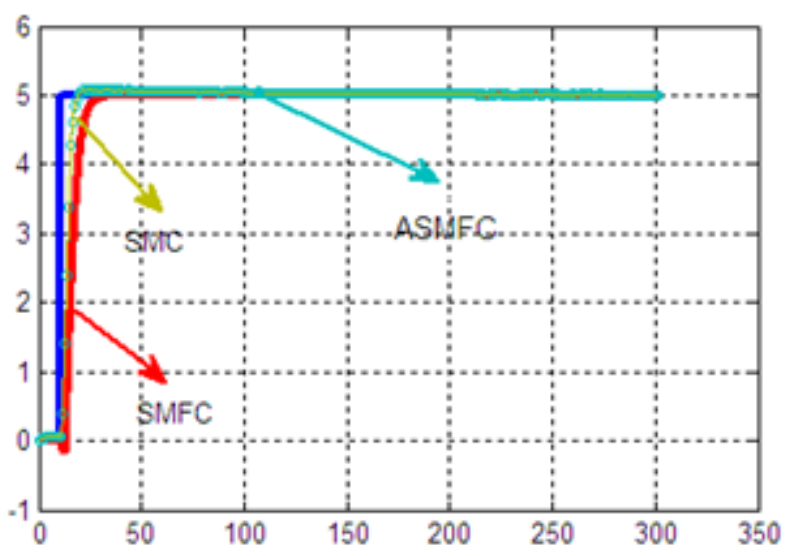

Fig. 7: Third link trajectory without disturbance 
Disturbance rejection: Figures 8, 9 and 10 have shown the power disturbance elimination in SMC, SMFC and ASMFC. The main target in this controller is disturbance rejection as well as the other responses. A band limited white noise with predefined of $40 \%$ the power of input signal is applied to the Step SMC, SMFC and ASMFC. It found fairly fluctuations in trajectory responses. As mentioned earlier, SMC works very well when all parameters are known, this challenge plays important role to select the ASMFC as a based robust controller in this research.

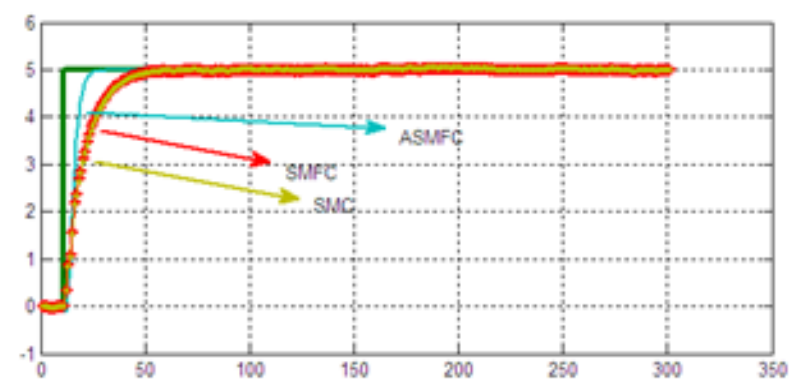

Fig. 8: First link trajectory with disturbance

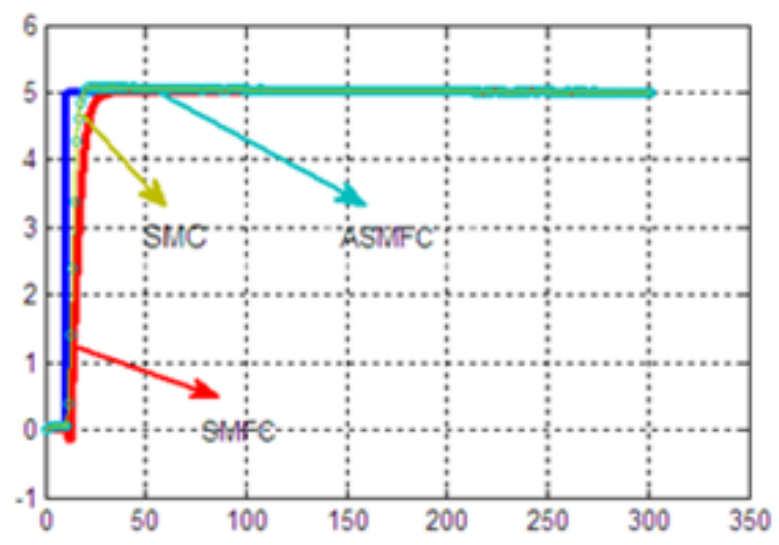

Fig. 9: Second link trajectory with disturbance

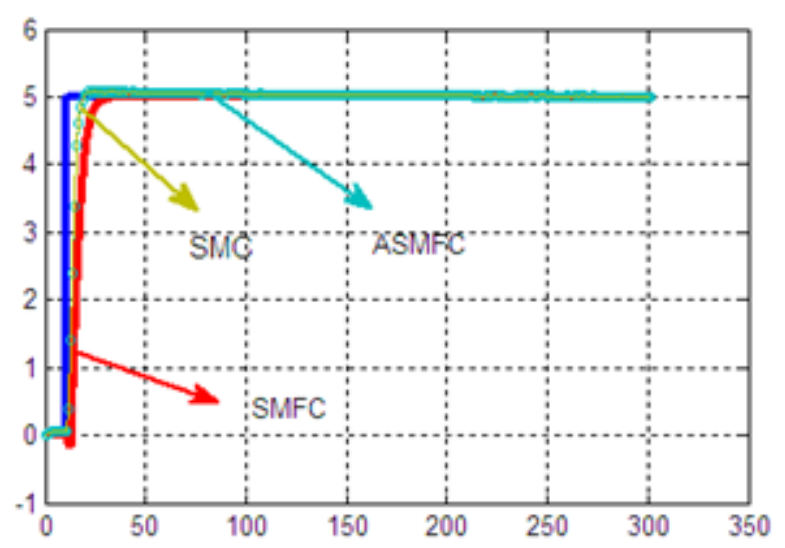

Fig. 10: Third link trajectory with disturbance

Among above graphs (8, 9 and 10) relating to Step trajectories following with external disturbance, SMC and SMFC have fairly fluctuations. By comparing some control parameters such as overshoot, rise time, steady state and RMS error it computed that the SMC's and SMFC's overshoot (1.8\%) is higher than ASMFC's $\mathbf{( 1 . 2 \% )}$, although all of them have about the same rise time; SMC and SMFC (0.5 sec) and ASMFC (0.41 sec), the Steady State and RMS error in ASMFC (Steady State error $=\mathbf{- 0 . 0 0 1 9}$ and $\mathbf{R M S}$ error $=\mathbf{0 . 0 0 2 5})$ is fairly lower than SMC and SMFC (Steady State error $\cong 0.005$ and $R M S$ error $=0.0042$ ).

\section{Conclusions:}

Refer to the research, a position adaptive sliding mode fuzzy control (STFSMC) design and application to robot manipulator has proposed in order to design high performance nonlinear controller in the presence of uncertainties. Regarding to the positive points in sliding mode controller, fuzzy logic controller and adaptive method, the output has improved. Each method by adding to the previous method has covered negative points. The main target in this research is analyses and design of the position controller for first three links of PUMA robot manipulator to reach an acceptable performance. In the first part studies about classical sliding mode controller (SMC) which shows that: although this controller has acceptable performance with known dynamic parameters but by comparing the performance regard ing to uncertainty, the SMC's output has fairly fluctuations and slight oscillation. Although SMC has many advantages such as stability and robustness but there are two important disadvantages as below: chattering phenomenon and mathematical nonlinear dynamic equivalent controller part. Second step focuses on applied fuzzy logic method in sliding mode controller to solve the stability and robustness in pure fu zzy logic controller. In this part Mamdani's error based controller has considered with one input $(\mathbf{S})$ and an output. This controller is independent of nonlinear mathematical dynamic parameters and easier to implement. Controller design is done by using 7 rules Mamdani's fuzzy sliding mode controller, adjusting the expert knowledge's and try and error method. This controller works very well in certain environment but if it works in uncertain area or various dynamic parameters, it has slight chattering phenomenon. The system performance in sliding mode controller and sliding mode fuzzy controller are sensitive to the sliding surface slope. Therefore, compute the optimu m value of sliding surface slope for a system is the third important challenge work. This problem has solved by adjusting surface slope of the sliding mode controller continuously in real-time. In this way, the overall system performance has improved with respect to the classical sliding mode controller. By comparing between adaptive sliding mode fuzzy controller and sliding mode fuzzy controller, found that adaptive sliding mode fuzzy controller has steadily stabilised in output response (e.g., torque performance) but sliding 
mode fuzzy controller has slight chattering in the presence of uncertainties.

\section{References}

[1] Slotine J. J. E., and W. Li., 1991. Applied nonlinear control, Prentice-Hall Inc.

[2] Kurfess T. R, 2005. Robotics and automation handbook, CRC Press.

[3] OKYAY KAYNAK., 2001. Guest Editorial Special Section on Computationally Intelligent Methodologies and Sliding-Mode Control. IEEE TRANSACTIONS ON INDUSTRIAL ELECTRONICS, 48(1): 2-3.

[4] Wang L. X., 1993. Stable adaptive fuzzy control of nonlinear systems. IEEE Trans. Fuzzy systems, 1(2): 146-154.

[5] Shahnazi R., H. Shanechi, N. Pariz, 2006. Position control of induction and servomotors: A novel adaptive fuzzy PI sliding mode control, IEEE Conferences on power engineering, P.P: 1-9.

[6] Medhaffar H., N. Derbel, and T. Damak, 2006. A decoupled fuzzy indirect adaptive sliding mode controller with application to robot manipulator, Int. Journal on modeling, identification and control, 1(1): 23-29.

[7] Siciliano B, and Khatib O, 2007. Handbook of robotics, Springer.

[8] Emami M. R., Turksen I. B., and Goldenberg A. A., 1998. Development of a systematic methodology of fuzzy logic modelling, IEEE Trans. On fuzzy systems, 6(3):346-361.

[9] Zhang X., and Z. Man, 2000. A new fuzzy sliding mode control scheme, 3rd world congress on intelligent control and automation, P.P: 1692-1696.

[10] Shahnazi R., H. Shanechi, N. Pariz, 2008. Position control of induction and servomotors: A novel adaptive fuzzy PI sliding mode control, IEEE Journals on energy conversions, 23(1): 138-147.

[11] Weng C. C., W. S. Yu, 2008. Adaptive fuzzy sliding mode control for linear time-varying uncertain systems, IEEE conference on fuzzy systems, P.P: 1483-1490.

[12] Yu Z. X, 2009. Adaptive sliding mode-like fuzzy logic control for nonlinear systems, Journal of communication and computer, 6(1): 53-60.

[13] Sh. Tayebi Haghighi, S. Soltani, Farzin Piltan, M. kamgari, S. Zare, "Evaluation Performance of IC Engine: Linear Tunable Gain Computed Torque Controller Vs. Sliding Mode Controller", International Journal of Intelligent Systems and Applications, 5(6), 2013.
[14] Farzin Piltan, N. Sulaiman, Atefeh Gavahian, Samira Soltani \& Samaneh Roosta, "Design Mathematical Tunable Gain PID-Like Sliding Mode Fuzzy Controller with Minimum Rule Base", International Journal of Robotic and Automation, 2 (3): 146-156, 2011.

[15] Farzin Piltan, N. Sulaiman, S.Soltani, M. H. Marhaban \& R. Ramli, "An Adaptive Sliding Surface Slope Adjustment in PD Sliding Mode Fuzzy Control For Robot Manipulator", International Journal of Control and Automation, 4 (3): 65-76, 2011.

[16] Farzin Piltan, N. Sulaiman, Samaneh Roosta, Atefeh Gavahian \& Samira Soltani, "Evolutionary Design of Backstepping Artificial Sliding Mode Based Position Algorithm: Applied to Robot Manipulator", International Journal of Engineering, 5 (5):419-434, 2011.

[17] Farzin Piltan, N. Sulaiman, Atefeh Gavahian, Samaneh Roosta \& Samira Soltani, "On line Tuning Premise and Consequence FIS: Design Fuzzy Adaptive Fuzzy Sliding Mode Controller Based on Lyaponuv Theory", International Journal of Robotics and Automation, 2 (5):381-400, 2011.

[18] Farzin Piltan, N. Sulaiman, Samira Soltani, Samaneh Roosta \& Atefeh Gavahian, "Artificial Chattering Free on-line Fuzzy Sliding Mode Algorithm for Uncertain System: Applied in Robot Manipulator", International Journal of Engineering, 5 (5):360-379, 2011.

[19] Farzin Piltan, F. Aghayari, M. Rashidian \& M.Shamsodini, "A New Estimate Sliding Mode Fuzzy Controller for RoboticManipulator", International Journal of Robotics and Automation, 3 (1):45-60, 2012.

[20] Farzin Piltan, A. Hosainpour, E. Mazlomian, M.Shamsodini, M.H Yarmahmoudi. "Online Tuning Chattering Free Sliding Mode Fuzzy Control Design: Lyapunov Approach", International Journal of Robotics and Automation, 3(3):77-105, 2012.

[21] Farzin Piltan, M.H. Yarmahmoudi, M. Shamsodini, E.Mazlomian, A.Hosainpour. "PUMA-560 Robot Manipulator Position Computed Torque Control Methods Using MATLAB/SIMULINK and Their Integration into Graduate Nonlinear Control and MATLAB Courses", International Journal of Robotics and Automation, 3(3): 167-191, 2012.

[22] Farzin Piltan, M.R. Rashidian, M. Shamsodini and S. Allahdadi." Effect of Rule Base on the FuzzyBased Tuning Fuzzy Sliding Mode Controller: Applied to 2nd Order Nonlinear System", International Journal of Advanced Science and Technology, 46:39-70, 2012. 


\section{Authors' Profiles}

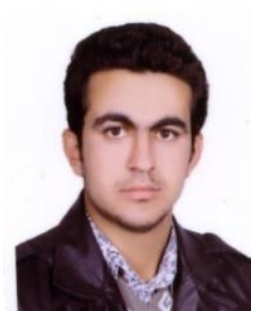

Mohammad Shamsodini is currently working as a co researcher in Control and Robotic $\mathrm{Lab}$ at the institute of advance science and technology, SSP research and development institute. His current research interests are in the area of nonlinear control, artificial control systemand robotics.

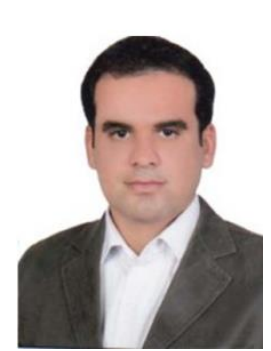

Rouholla Manei is a lecturer at Electrical Engineering department at IAU, Bushehr, Iran.

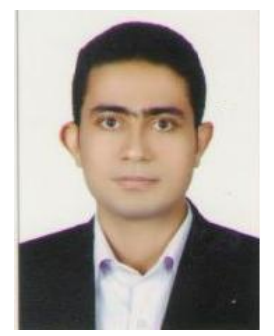

Ali Bekter is a lecturer at Electrical Engineering department at IAU, Bushehr, Iran.

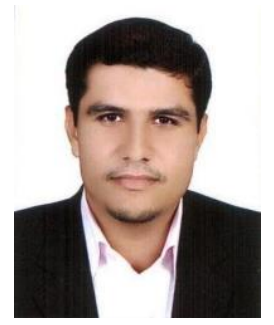

Babak ranjbar is a lecturer at Electrical Engineering department at IAU, Bushehr, Iran.

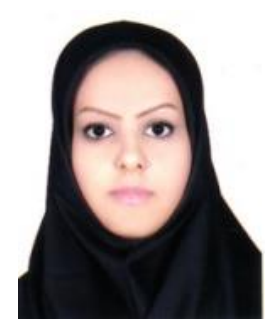

Samira Soltani is currently working as a co researcher in Control and Robotic Lab at the institute of advance science and technology, SSP research and development institute. She is the main author of more than 8 scientific papers in refereed journals. Her current research interests are in the area of nonlinear control, artificial control system and robotics.
How to cite this paper: Mohammad Shamsodini, Rouholla Manei, Ali Bekter, Babak Ranjbar, Samira Soltani,"Design a New Fuzzy Optimize Robust Sliding Surface Gain in Nonlinear Controller", International Journal of Intelligent Systems and Applications(IJISA), vol.5, no.12, pp.91-98, 2013. DOI: 10.5815/ijisa.2013.12.08 